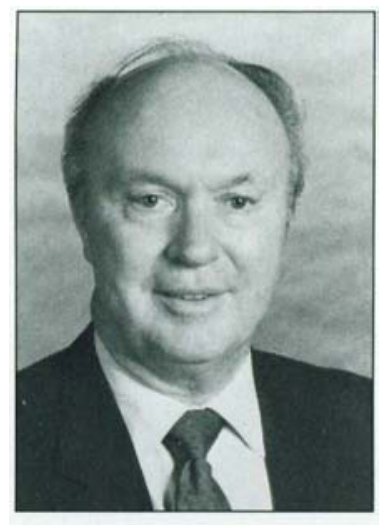

KENNETH R. FARRELL

Vice President

Agriculture and Natural Resources

\title{
The 1990 Farm Bill sets new courses for agriculture
}

In late October, the Congress completed the omnibus Food, Agriculture, Conservation, and Trade Act of 1990 (FACT-90), generally referred to as the 1990 Farm Bill. This massive and complex legislation sets the course of national public policy for the agricultural sector for the next five years.

Virtually every facet of the national agricultural economy will be impacted by the voluminous provisions of the legislation - commodity price supports, food and nutrition, forestry, natural resource conservation and the environment, foreign trade and food aid, rural development, and farm labor and credit. Enacted under the shadow of budget reconciliation pressures to reduce the federal deficit, and after months of often rancorous debate, the new farm bill reflects compromise among many competing interests.

Although change in national policy tends to be incremental and evolutionary by the very nature of the governmental process, the cumulative effect of such change over decades can be substantial. And so it is with FACT-90.

Relative to the farm bill of a decade ago, the new law reflects a substantial "greening" of agricultural policy. Provisions to protect highly erodible lands, wetlands, and other environmentally sensitive lands and to improve water quality have been extended and strengthened. An Office of Environmental Quality will be established in USDA to evaluate the environmental effects of agricultural programs and to coordinate and monitor efforts to improve environmental quality. Other provisions include mandatory recordkeeping on pesticide use; national standards for farm products labeled "organic;" assessment of the effects of global climate change on agriculture and forestry; a pilot program to promote the preservation of farmland threatened with conversion to other uses; and measures to protect forestland. Natural resource and environmental dimensions are clearly in ascendancy in agricultural policy. In an effort to reduce the costs of annual farm appropriation bills, the new law reduces the amount of acreage eligible for price and income support by $15 \%$ through a so-called "triple base program." In effect, it is a $15 \%$ reduction in direct payments to farmers. These provisions are projected to cost $\$ 41$ billion over five years, compared to realized costs of $\$ 80$ billion from the 1985 Farm Bill.

Of particular interest to the University of California and other land-grant universities are the provisions of Title XIV, the science and education section. Among major new or expanded programs are:

- a national competitive agricultural research initiative, with an authorization that increases from the current level of $\$ 150$ million to $\$ 500$ million in 1995

- increased agricultural research facilities grants, growing from \$20 million to \$50 million annually through 1995

- an Agricultural Science and Technology Review Board to assess science and technology transfer issues that have implications for agriculture, the environment, human nutrition, and rural and urban communities

- a competitive grants program for veterinary medicine facilities
- a competitive grants program for international trade development centers

- a requirement that institutions receiving extension funds have guidelines that minimize conflicts of interest

- a new sustainable agriculture research and extension subtitle aimed at reducing the use of chemicals and toxic substances in agricultural production

- a federal-state matching grant program toencourage adoption of sustainable agricultural practices, authorizing $\$ 40$ million annually for related research

- a national program requiring that all extension advisors or agents be trained in sustainable agriculture by 1995

- a National Genetics Resources Program to collect, preserve, and disseminate genetic material important to agriculture

- a post-harvest research program for the production, preparation, processing, handling, and storage of agricultural products

- a research program in integrated pest management and a research and grant program for control of exotic pests

- reservation extension agents to provide service for Indian tribal jurisdictions

- a five-year pilot project in at least two states to coordinate the delivery of nutrition education involving the Expanded Food and Nutrition Education Program (EFNEP)

- strengthened communication networks for extension, resident instruction, and research; national centers for product quality research; and biotechnology risk assessment

In another major title, the farm bill creates a new rural development agency in USDA. Among other provisions, it authorizes expanded research and extension programs, including training to assist rural residents in business matters, leadership development, family health, and farm safety.

The FACT-90 gives substantial discretion to the Secretary of Agriculture as to whether and how some programs will be implemented. Funding is dependent on the annual appropriations process.

As complex and comprehensive as is the FACT-90, other public policies not under the jurisdiction of Congressional agriculture committees have important implications for California agriculture, natural resources, rural people, and communities. Among the policies that will impact agriculture further are clean air and water, health, education, and environmental policies.

Although the 1990 Farm Bill contributes notably to the development of comprehensive publicpolicies based on theinterdependency of agriculture with other sectors, those policies alone are not sufficient to deal with the increasing complexities of agriculture in a dynamic, rapidly changing world. Agriculture must adapt rapidly to changing market, political, and scientific conditions to remain healthy through the 1990 s. The farm bill obviously does not please everyone, but it does provide some new opportunities that could benefit agriculture and the nation as a whole. 